\title{
THE GRAPHIC CONFIGURATION OF INNOCENT SYSTOLIC MURMURS
}

\author{
BY \\ BERTRAND WELLS \\ From St. Bartholomew's Hospital and the National Heart Hospital
}

Received January 27, 1956

The systolic murmurs heard in healthy subjects used to be called "functional" murmurs. White et al. (1942) recommended the term " physiologic." Evans (1947) called these murmurs " innocent." Others have called them " incidental," "accidental," or " murmurs of unknown origin."

The decision that a systolic murmur is innocent usually depends not only on the character of the murmur itself, but also on the absence of any evidence of organic heart disease. The improvement in the technique of phonocardiography during the last decade provides a means whereby the innocent systolic murmurs can be studied more objectively. Such a study should lead to more accurate diagnosis, to a more useful classification, and perhaps to an explanation of the production of these murmurs. Bass et al. (1933) found that innocent systolic murmurs were composed only of high-frequency vibrations and this differentiated them from organic murmurs which were composed of both low- and high-frequency vibrations. Evans (1948) clearly demonstrated the brief duration of innocent systolic murmurs by phonocardiography, and later (1951) he stated that "A detection of the frequency of the separate murmurs may also contribute to a readier recognition of the innocent ones from amongst the others." Evans (1948) also described the phonocardiogram of the late systolic murmur. Harris et al. (1949) studied the phonocardiogram of children with mitral regurgitation and children with innocent systolic murmurs; they described the short duration and "vibratory" nature of the innocent murmur, and noted the similarity of pattern to that produced by a tuning fork. Harris and Friedman (1952) collected 28 tracings of " vibratory" systolic murmurs in children, and Boldrini et al. (1954) added a further 20 tracings. The latter workers found the duration of the murmur was between 0.07 and 0.12 seconds. Other workers (Wood, 1950; Gmachl, 1953; and Wells, 1954) have published tracings of innocent systolic murmurs.

The object of the present study is to describe the appearance on the phonocardiogram of innocent systolic murmurs. The appearance should be of value in the diagnosis and explanation of innocent systolic murmurs, and should help in the differentiation of such murmurs from the murmurs of organic heart disease.

\section{MATERIAL}

The study consists of the clinical and phonocardiographic findings in 70 healthy subjects. Their ages varied between 5 and 56 years, and 36 were males and 34 females. They are consecutive cases on whom phonocardiograms were taken when there was a clinical diagnosis, supported by X-ray screening and electrocardiography, of innocent systolic murmur. Ten of the subjects had a murmur in late systole in the mitral area. There is some evidence that subjects with this murmur may later develop subacute bacterial endocarditis or mitral incompetence (Brigden and Leatham, 1953). Their innocent nature has been assumed by Evans (1948), and has been assumed in this study because such a murmur has never been found in 1000 phonocardiograms on patients with heart disease. 
The material is not unselected because phonocardiograms were not taken on every subject with an innocent systolic murmur. It is therefore possible that the preponderance of innocent systolic murmurs in the mitral and præcordial areas is partly due to the fact that the innocent murmurs in the pulmonary area are more easily dismissed as of no importance. It is also possible that the cases chosen include an undue proportion of murmurs of moderate intensity rather than those of slight intensity. In no case was the murmur clinically louder than Grade 3 (grading of Levine, 1933).

In order to contrast innocent murmurs with the murmurs of organic heart disease 18 cases of aortic stenosis have been analysed in a similar way. The patients were between 6 and 77 years of age, and 11 were males and 7 females.

\section{METHOD}

The tracings were taken on a Sanborn phonocardiograph using a logarithmic frequency response and a paper speed of $75 \mathrm{~mm}$. a second. The routine locations for the microphone were the mitral and pulmonary areas and the fourth left interspace at the left sternal border, and also the area of maximal intensity of the murmur. The gain of the amplifier was not altered when the microphone was moved from one location to the next so that the relative intensity of the murmur might be estimated from the tracings. At least eight heart beats were recorded at each location so that the non-cardiac vibrations could be identified. The precautions necessary to obtain satisfactory tracings have been described earlier (Wells et al., 1949).

The timing of the murmur in systole was measured from the onset of the maximal vibrations of the first heart sound. This is the beginning of the second component of the first heart sound and represents the time of closure of the mitral valve. The intervals measured were from this point to the beginning and end of the murmur, to its point of maximal intensity, and to the beginning of the second heart sound. The last figure was taken as the duration of systole, and was recorded together with the cycle length taken from the synchronous electrocardiogram.

The frequency of the vibrations constituting the murmur was measured by counting with the help of a hand lens the number of waves in one-tenth of a second. Vibrations that were slurred were counted as single, and vibrations that were distinctly notched were counted as two.

No measurement has been made of the absolute intensity of the vibration, or of their intensity relative to the heart sounds.

\section{RESULTS}

The seventy cases fall into three main groups. They are distinguished by the location of the maximal intensity and by the graphic configuration of the murmur.

(1) Innocent pracordial murmurs, occurring in an area from just within the apex beat to the left sternal border between the third and fifth intercostal spaces. They are divided on phonocardiographic appearances into two groups.

Coarse variety, composed of uniform vibration of low frequency. The vibrations start early in systole and usually rise smoothly and rapidly to a maximal intensity which is slightly earlier in systole than is the case in aortic stenosis. The intensity usually falls off as smoothly though less rapidly, and the murmur ends before or just after mid-systole. This coarse variety of innocent præcordial murmur is that described by Harris as "vibratory." Examples of the murmur are shown in Fig. 1.

Fine variety, composed of irregular vibrations of intermediate frequency. These murmurs resemble the ejection murmurs of aortic or pulmonary stenosis except for the fact that they are of shorter duration and are slightly earlier in systole. Examples are shown in Fig. 2.

(2) Late systolic murmurs, all of which are maximal in the mitral area. They are composed of high-frequency vibrations starting after mid-systole and increasing in intensity in a crescendic manner. The reasons for considering these murmurs innocent have already been stated. Examples of these murmurs are shown in Fig. 3.

(3) Innocent murmurs in the pulmonary area, having their maximal intensity in the second left interspace, and being composed of vibrations of intermediate frequency. These murmurs resemble the fine variety of innocent præcordial murmur except that they are of longer duration. The duration is, however, shorter than that of the murmur of aortic stenosis. Examples of innocent murmurs in the pulmonary area are shown in Fig. 4. 


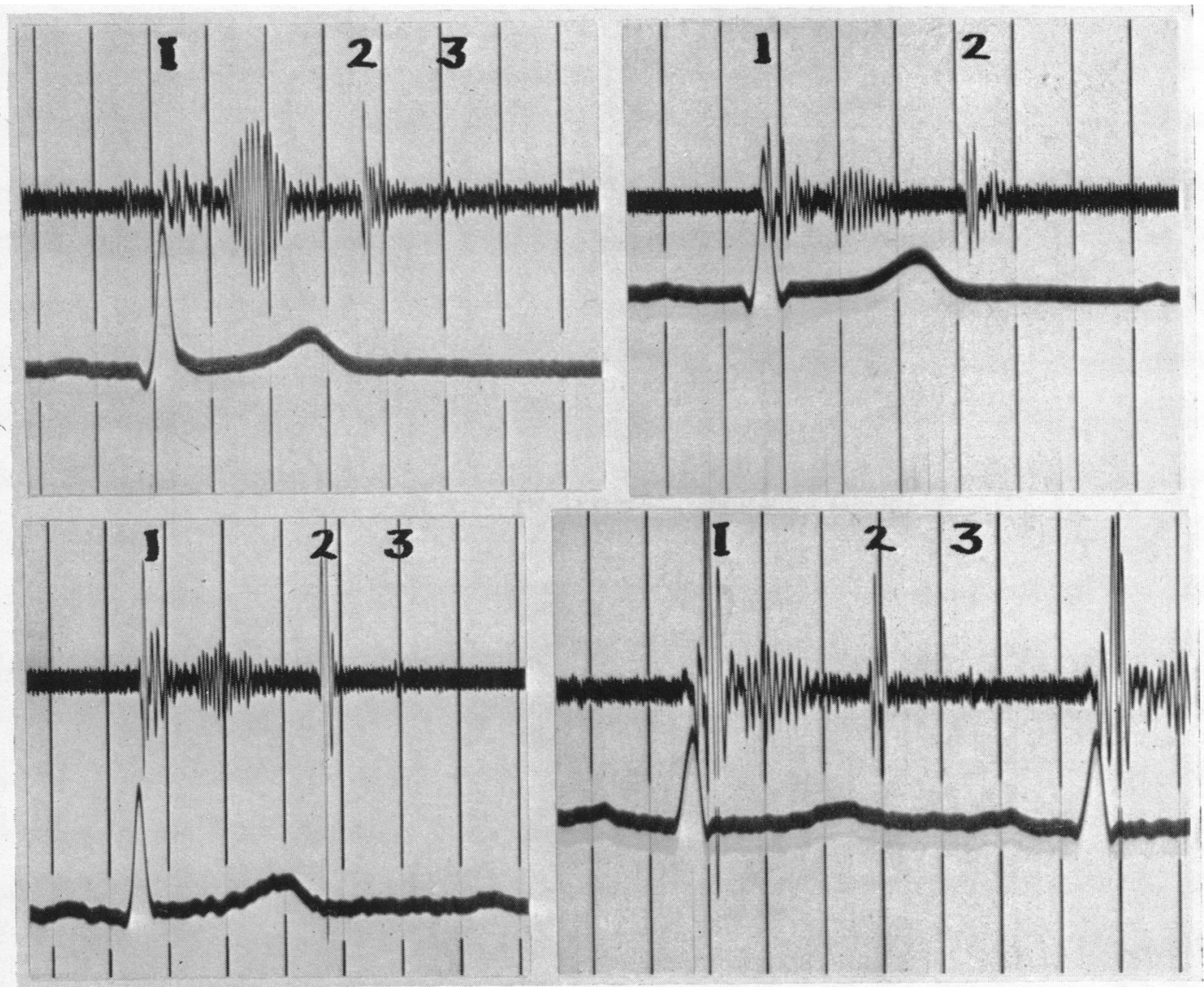

FIG. 1.-Coarse Variety of Innocent Pracordial Murmur. Logarithmic phonocardiograms of four subjects with innocent præcordial murmurs of the coarse variety, showing regular vibrations of low frequency. Reference tracings electrocardiogram, lead II. Time lines $0 \cdot 1 \mathrm{sec}$.

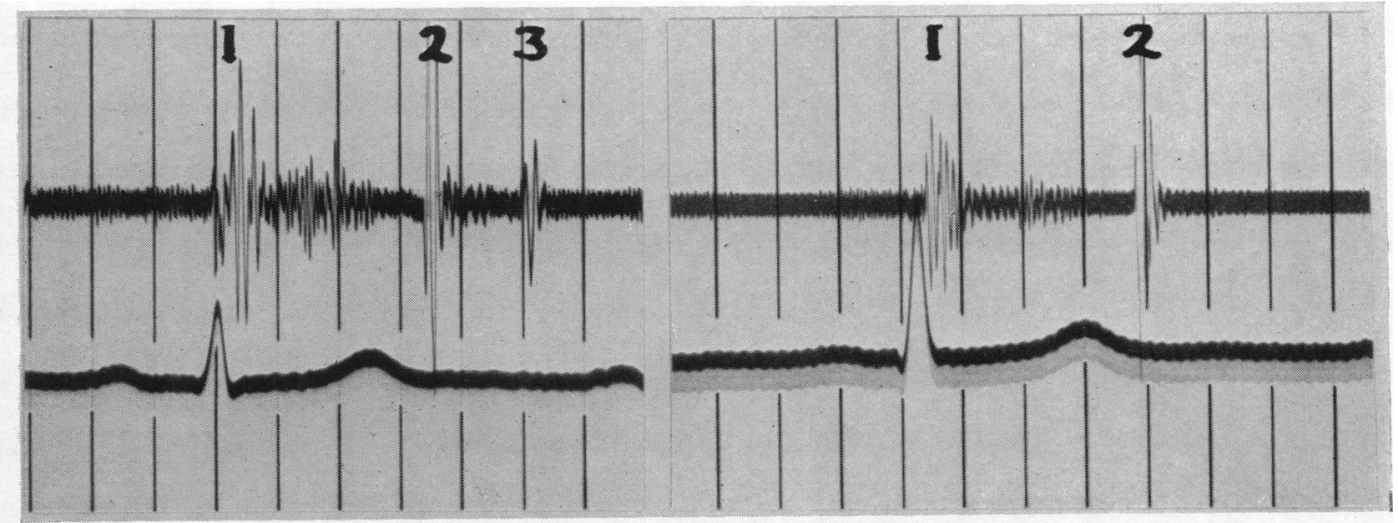
Fig. 2.-Fine Variety of Innocent Pracordial Murmur. Logarithmic phonocardiograms of two subjects with
innocent præcordial murmurs of the fine variety, showing irregular vibrations of intermediate frequency. Reference tracings as for Fig. 1. 


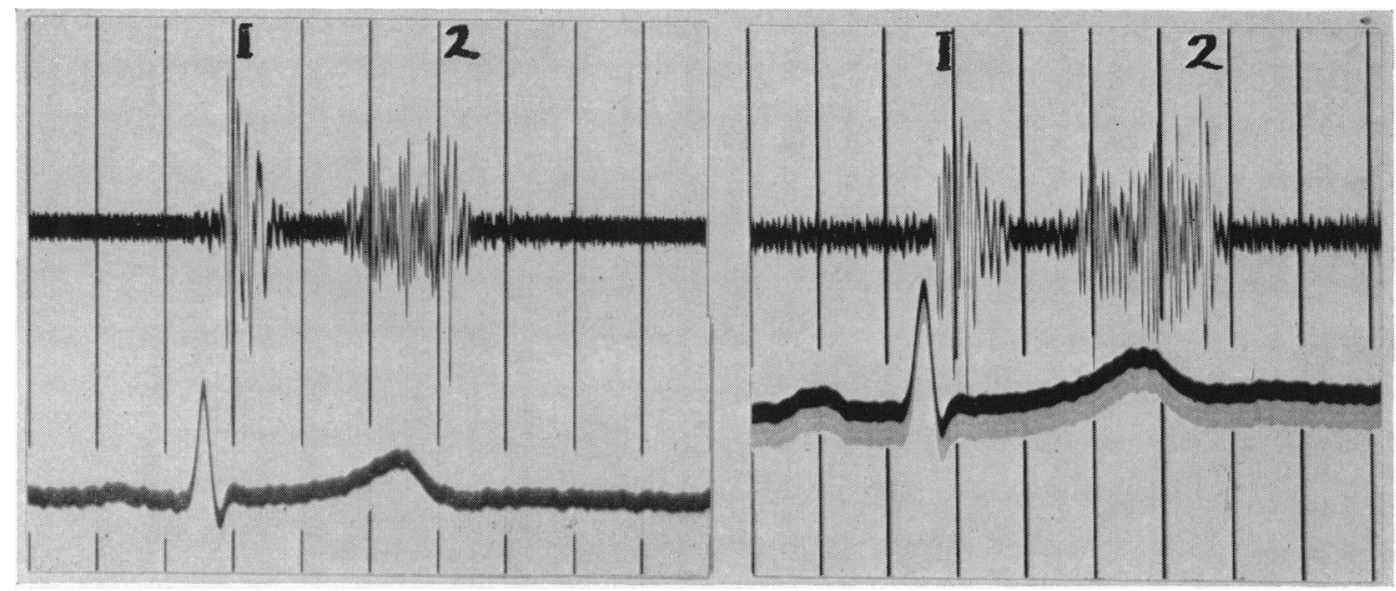

FIG. 3.-Late Systolic Murmurs. Logarithmic phonocardiograms of two subjects with late systolic murmurs. The vibrations are of high frequency and do not start until the second half of systole. Reference tracings as for Fig. 1.

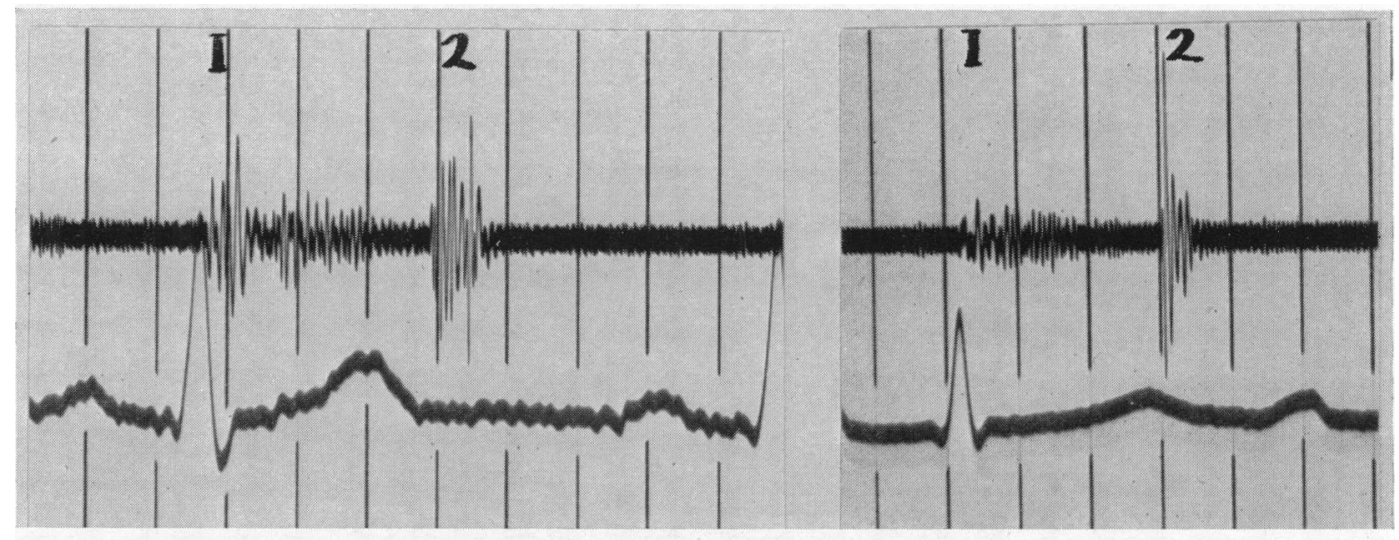

FIG. 4.-Innocent Systolic Murmurs in the Pulmonary Area. Logarithmic phonocardiograms of two subjects with innocent systolic murmurs in the pulmonary area. The vibrations are irregular and of intermediate frequency and of slightly longer duration than in the other innocent systolic murmurs. Reference tracings as for Fig. 1.

The age of the patients in each group is shown in the Table. The only inference that may be drawn from such a series is that each murmur may be found at any time from childhood to adult life. Evans (1955) believes that the only innocent systolic murmurs heard after the age of 40 are the murmurs in late systole. There are two exceptions to this in the present series. The first is a man of 48 with a coarse præcordial systolic murmur and no evidence of heart disease: such a murmur might readily be attributed to aortic sclerosis (deformity of the aortic valve cusps without narrowing), but in this case it was considered innocent because it was coarse and brief, and showed on the phonocardiogram as regular vibrations of low frequency. The second exception is a woman of 56 with a brief præcordial murmur in early systole; in this case the murmur was considered innocent because it had been present for twenty years without evidence of heart disease.

The duration of all innocent systolic murmurs is brief. The longest murmur is that in the pulmonary area and this murmur is of shorter duration than the murmur of aortic stenosis. The murmur of aortic stenosis has a duration of between 0.18 and $0.25 \mathrm{sec}$., while that of the innocent murmur in the pulmonary area is between $0 \cdot 15$ and $0.20 \mathrm{sec}$. The innocent præcordial murmur 
TABLE

Table showing the age of the subjects, the time relationships of the murmurs, and the frequency of the vibrations in cycles a second. The upper figures are mean values and the lower figures in brackets are the maximum and minimum values

\begin{tabular}{|c|c|c|c|c|c|c|c|c|c|}
\hline $\begin{array}{l}\text { Type } \\
\text { of } \\
\text { murmur }\end{array}$ & $\begin{array}{l}\text { No. } \\
\text { of } \\
\text { cases }\end{array}$ & $\begin{array}{c}\text { Age } \\
\text { of } \\
\text { patients }\end{array}$ & $\begin{array}{c}\text { Length } \\
\text { of } \\
\text { murmur }\end{array}$ & $\begin{array}{r}\begin{array}{l}\text { Length } \\
\text { of } \\
\text { systole }\end{array} \\
\text { (In }\end{array}$ & $\begin{array}{c}\text { Length } \\
\text { of } \\
\text { cycle }\end{array}$ & $\begin{array}{l}\begin{array}{c}\text { Onset } \\
\text { of } \\
\text { murmur }\end{array} \\
\text { of a seco }\end{array}$ & $\begin{array}{l}\begin{array}{c}\text { End } \\
\text { of } \\
\text { murmur }\end{array} \\
\text { nd) }\end{array}$ & $\begin{array}{c}\text { Peak } \\
\text { of } \\
\text { intensity }\end{array}$ & $\begin{array}{c}\text { Frequency } \\
\text { of } \\
\text { murmur }\end{array}$ \\
\hline $\begin{array}{l}\text { Præcordial: Coarse } \\
\text { variety }\end{array}$ & 40 & $\begin{array}{c}14 \\
(3-48)\end{array}$ & $\begin{array}{c}10 \\
(8-13)\end{array}$ & $\begin{array}{c}32 \\
(25-38)\end{array}$ & $\begin{array}{c}84 \\
(59-135)\end{array}$ & $\begin{array}{c}10 \\
(5-12)\end{array}$ & $\begin{array}{l}20 \\
(14-25)\end{array}$ & $\begin{array}{c}15 \\
(9-18)\end{array}$ & $\begin{array}{c}110 \\
(75-160)\end{array}$ \\
\hline Fine variety & 10 & $\begin{array}{c}29 \\
(2-56)\end{array}$ & $\begin{array}{c}11 \\
(9-12)\end{array}$ & $\begin{array}{c}32 \\
(23-38)\end{array}$ & $\begin{array}{c}81 \\
(47-105)\end{array}$ & $\begin{array}{c}9 \\
(5-13)\end{array}$ & $\begin{array}{c}20 \\
(15-22)\end{array}$ & $\begin{array}{c}14 \\
(10-16)\end{array}$ & $\begin{array}{c}170 \\
(120-240)\end{array}$ \\
\hline Late systolic & 10 & $\begin{array}{c}32 \\
(11-51)\end{array}$ & $\begin{array}{c}14 \\
(12-17)\end{array}$ & $\begin{array}{c}35 \\
(30-39)\end{array}$ & $\begin{array}{c}97 \\
(70-115)\end{array}$ & $\begin{array}{c}21 \\
(20-22)\end{array}$ & $\begin{array}{c}35 \\
(30-49)\end{array}$ & $\begin{array}{c}29 \\
(25-35)\end{array}$ & $\begin{array}{c}220 \\
(200-260)\end{array}$ \\
\hline Pulmonary & 10 & $\begin{array}{c}16 \\
(5-30)\end{array}$ & $\begin{array}{c}16 \\
(15-20)\end{array}$ & $\begin{array}{c}31 \\
(26-35)\end{array}$ & $\begin{array}{c}80 \\
(65-96)\end{array}$ & $\begin{array}{c}8 \\
(5-10)\end{array}$ & $\begin{array}{c}24 \\
(23-25)\end{array}$ & $\begin{array}{c}15 \\
(8-18)\end{array}$ & $\begin{array}{c}170 \\
(130-230)\end{array}$ \\
\hline Aortic stenosis & 18 & $\begin{array}{c}36 \\
(6-77)\end{array}$ & $\begin{array}{c}21 \\
(18-25)\end{array}$ & $\begin{array}{c}33 \\
(30-36)\end{array}$ & $\begin{array}{c}87 \\
(64-120)\end{array}$ & $\begin{array}{c}6 \\
(4-11)\end{array}$ & $\begin{array}{c}27 \\
(25-30)\end{array}$ & $\begin{array}{c}17 \\
(12-20)\end{array}$ & $\begin{array}{c}210 \\
(180-300)\end{array}$ \\
\hline
\end{tabular}

and the late systolic murmur are so brief that this is one of their most characteristic features. The longest of these murmurs is $0.17 \mathrm{sec}$. which is shorter than the shortest murmur of aortic stenosis $(0.18 \mathrm{sec}$.$) .$

The timing in the cardiac cycle is an important feature of innocent systolic murmurs. The late systolic murmur can be immediately identified because it does not start until the second half of systole. The other innocent murmurs begin early in systole and occupy more of the first half of systole than the second half. This usually enables these murmurs to be differentiated from murmurs of organic heart disease. In every case in this series the murmur ends within $0.25 \mathrm{sec}$. after the beginning of the major vibrations of the first heart sound, and in none of the cases of aortic stenosis did the murmur end before this time.

The maximal intensity of the late systolic murmur is near the second sound. In the other innocent systolic murmurs the maximal intensity is usually before mid-systole. Although this feature does not help much in differentiating an innocent murmur from a murmur of organic heart disease it may throw light on the mode of production of the murmur.

The frequency of the vibrations constituting the innocent systolic murmur is interesting. The late systolic murmur has a high frequency of between 200 and 260 cycles a second. This is the same frequency as is found in the murmur of mitral regurgitation. It would be tempting to attribute the late systolic murmur to a fine regurgitant stream through the mitral valve. In further support is the fact that the murmur of mitral regurgitation is sometimes louder in the second half of systole than the first. Despite these findings a genuine late systolic murmur (that is one in which the phonocardiogram shows no murmur in early systole) has been considered innocent. This is because it was never found in conjunction with evidence of mitral valve disease or of cardiac enlargement.

The coarse variety of innocent præcordial murmur is composed of low-frequency vibrations between 75 and 160 cycles a second. Moreover, the vibrations are quite regular and contain no high-frequency components at all. This pattern is pathognomonic of an innocent murmur. It suggests that the murmur is not due to turbulence of the blood, but that it comes from a vibration of the heart muscle itself. Regular vibrations of low frequency are never found in organic heart disease, although regular vibrations of high frequency occur in cases of rupture of an aortic or mitral valve cusp. 
The fine variety of innocent præcordial murmur is composed of irregular vibrations of intermediate frequency (120 to 240 cycles/sec.). It is maximal below the pulmonary area and of shorter duration than the murmur in the pulmonary area, but not distinguishable in any other way. The close resemblance of these murmurs suggests that they are produced in a similar way. This is probably a turbulence in the blood stream at the time of rapid increase in the rate of blood flow.

\section{Discussion}

The three types of innocent systolic murmur that are described in this study constitute the simplest classification possible from the point of view of phonocardiography. The change in these murmurs with posture and respiration is an important feature in auscultation, but it is possible to establish the innocent nature of the murmurs by phonocardiography without such manœuvres. The frequent occurrence of the coarse variety of præcordial murmur explains the buzzing or twanging character so often heard on auscultation. The uniform and low frequency of the vibrations explains the changes often noted when the pressure of the chestpiece of the stethoscope on the skin is varied. It is for this reason that the murmur is sometimes considered to be exocardial. The nature of the vibrations suggests, however, that they come from the heart wall during ventricular contraction. When the murmur is loud it may often be mistaken for the murmur of ventricular septal defect.

\section{SUMMARY}

Seventy healthy subjects with innocent systolic murmurs have been studied by phonocardiography in order to establish the value of this investigation in the diagnosis, classification, and explanation of these murmurs. Eighteen patients with aortic stenosis have been studied in the same way in order to contrast the innocent murmurs with those of organic heart disease.

The inocent murmurs fell into three groups.

(1) Innocent pracordial murmurs of brief duration ending soon after mid-systole. These were divided on phonocardiographic appearances into coarse and fine varieties depending on the frequency of vibration.

(2) Late systolic murmurs, confined to the mitral area, not beginning until mid-systole, and composed of high-frequency vibrations.

(3) Innocent murmurs in the pulmonary area, often with some accentuation and delay of the pulmonary component of the second heart sound. The vibrations do not differ from those of the fine variety of præcordial murmur, but the duration of the murmur is slightly longer.

The phonocardiogram is of value in the diagnosis of innocent systolic murmurs. The pattern of the coarse variety of præcordial murmur is characteristic and prevents the erroneous diagnosis of pulmonary or aortic valve disease, or even of ventricular septal defect. The late systolic murmur can only be accepted as innocent when in the tracing the first half of systole is quite free from any murmur.

I am very grateful to Dr. Geoffrey Bourne and Dr. William Evans for their help and advice, and for their permission to describe the patients who were under their care.

\section{REFERENCES}

Bass, M. H., Mond, H., Messeloff, C. R., and Oppenheimer, E. T. (1933). J. Amer. med. Ass., 101, 17. Boldrini, R., Dallatorre, L., and Bocardelli, V. (1954). Progr. Med. Nap., 10, 193.

Brigden, W., and Leatham, A. (1953). Brit. Heart J., 15, 55.

Evans, W. (1947). Brit. Heart J., 9, 1 and 225.

(1948). Cardiology. Butterworth, London.

(1951). Lancet, 1, 1083.

- (1955). Personal communication.

Gmachl, H. (1953). Z. Krieslauff., 42, 503.

Harris, T. N., Friedman, S., and Haub, C. F. (1949). Pediatrics, 3, 845.

and Friedman, S. (1952). Amer. Heart J., 43, 707.

Levine, S. A. (1933). J. Amer. med. Ass., 101, 436.

Wells, B. G. (1954). Brit. med. J., $2,9$.

Rappaport, M. B., and Sprague, H. B. (1949). Amer. Heart J., 37, 586.

White, P. D., Adams, F. D., and Craib, D. (1942). Amer. J. med. Sci., 12, 203.

Wood, P. (1950). Diseases of the Heart and Circulation. Eyre and Spottiswoode, London. 